\title{
Considerações teórico-práticas sobre o ensino jurídico*
}

\author{
Plauto Faraco de Azevedo**
}

\section{DOS PRESSUPOSTOS TEÓRICOS}

Qualquer modificação ou reforma do currículo do ensino jurídico tem que ser precedida de uma avaliação de sua estrutura atual. Por outra parte, refletir sobre o ensino jurídico importa, sempre, em determinar e valorar a idéia prévia, que lhe subjaz e que o orienta. Esta idéia prévia do direito habitualmente não é explicitada. É ela a concepção positivista do direito, cuja gnoseologia limita o conhecimento do direito positivo a iuizos de constatação, pretendendo, assim, fundar sua cientificidade.

Segundo este ponto de vista, o trato do direito positivo, para ser científico, precisa ser rigorosamente separado de suas matrizes econômicas e políticas, daí resultando o divórcio entre o direito positivo e a realidade social. Por outras palavras, o que importa ao direito "cientificamente concebido" é o conhecimento estrito do ordenamento jurídico segundo os dados dele exclusivamente oriundos.

O mundo jurídico é separado do contexto histórico presente, conduzindo à convicção de que, se a sociedade vai mal, isto não diz respeito ao jurista, pois que lhe compete tão-só velar pelo mundo jurídico puro. É nesta visão que se insere a dogmática positivista, que se diz neutra, mas não consegue encobrir seu comprometimento ideológico.

É ideológico o pensamento que, pretendendo derivar unicamente de

\footnotetext{
* Considerações tecidas a pedido do Centro Acadêmico Hugo Simas, da Faculdade de Direito da Universidade Federal do Paraná.

* Doutor em Direito pela Universidade Católica de Louvain; ex-professor nos cursos de Graduação e Pós-Graduação stricto sensu da UFRGS; ex-pesquisador do CNPq.
} 
seus dados racionais, apresenta influência de dados sociais, particularmente econômicos, embora aquele que o formula possa disto não ter consciência. ${ }^{1}$ Dele resulta a adulteração do sentido dos fatos sociais reais.

Para evitar-se, tanto quanto é possível, o procedimento ideológico adulterador da compreensão dos fatos, cumpre, como ensinava Hermann Heller, evitar o trato das questões independentemente do quadro histórico a que pertencem, com interesse exclusivo em seu logicismo interno. ${ }^{2}$ A precisão conceitual, indispensável ao trato científico dos problemas, não se confunde com o culto do conceito pelo conceito, esquecido da realidade social. $\mathrm{Na}$ medida em que confunde o conceito com a realidade, a literatura jurídica revela-se não só não científica, mas também incondicionalmente comprometida com a manutenção do statu quo.

É claro que tal modo de pensar o direito positivo pode ser tranqüilizante, pois sua conexão com os fatos que regula, com seus valores e efeitos sociais, pode ser extremamente incômoda, particularmente em uma realidade como a presente, caracterizada pela exclusão, em que a iustiça distributiva tem servido meramente para uso retórico.
O estudo do direito tem que se orientar pelo acurado exame de suas fontes - da Constituição, de seus princípios orientadores, dos direitos fundamentais que ela prevê, dos diversos códigos compreendidos a partir de seus eixos fundamentais e da aplicação jurisprudencial que os vai ajustando às necessidades sociais, dos conceitos jurídicos fundamentais à compreensão da ordem jurídica global e dos conceitos jurídicos específicos a cada um de seus setores. E, como ensinava Kelsen, a ordem jurídica se estrutura em patamares de importância ascendente, culminando na Constituição.

Sem o domínio deste conhecimento nãoé possível atingir o "auditório" ao qual os profissionais do direito se dirigem. A argumentação, que constitui a base do raciocínio jurídico, ${ }^{3}$ perde-se na incomunicabilidade, tornando-se inútil.

Não é menos verdade que o estudo "dogmático" do direito, tendo em vista a determinação do sentido das normas, para posterior aplicação, precisa seguir a sua evolução doutrinária e jurisprudencial para chegar à sua significação presente. Acompanhar a evolução jurisprudencial é seguir a experiência histórica por que passam as normas, que não é, nunca foi, e jamais será neutra. Tampouco será

1 LALANDE, André. Vocabulaire technique et critique de la philosophie. 10. ed. rev. Paris: PUF, 1968, p. 459.

2 HELLER, Hermann. Teoria del estado. Prefácio. México: Fondo de Cultura Econômica, 1942. Passim.

3 PERELMAN, Chaim. Logique juridique: nouvelle réthorique. Paris: Dalloz, 1976. 
necessariamente lógica, ou poderá afastar as opções, vale dizer, as valorações perceptíveis em seu curso, através do tempo. ${ }^{4}$

Nem é por outra razão que Holmes, - notável juiz da Suprema Corte norteamericana, que muito contribuiu para a sedimentação do realismo jurídico e conseqüente negação do automatismo jurisdicional -, escreveu que "a vida do direito não tem sido lógica, mas experiência... a lei consubstancia a história do desenvolvimento de uma nação através de muitos séculos, não podendo ser tratada como se contivesse unicamente os axiomas ou corolários de um livro de matemática". ${ }^{5}$

O estudo da Ciência Jurídica não se pode resumir ao aprendizado acrítico do direito, sob pena de afastar o mundo dos juristas do mundo real, fazendo emergir o ceticismo do convívio de duas verdades - a do povo e a dos juristas. ${ }^{6}$ Neste sentido sua metodologia tem que ser revisada, de forma a incluir jornais, revistas, filmes, etc., a fim de que o aluno possa contextualizar a experiência jurídica.

Sendo inegável que o trabalho realizado pela dogmática jurídica seja dominantemente lógico-descritivo é, no entanto, desarrazoado estudar-se as leis ou os conceitos jurídicos segundo uma perspectiva exclusivamente lógica, indiferente à sua significação.

$\mathrm{O}$ autêntico estudo do direito é criativo e sensível ao quadro histórico a que se destina. Para isto, trata de unir as diferentes perspectivas do direito, ao invés de cindi-las, em nome de uma pseudo-ciência do direito.

O ensino e a aplicação do direito ligam-se inelutavelmente à sobrevivência do Estado e do padrão de relações humanas por ele protegidas. Embora esta asserção seja evidente, é difícil encontrá-la nos livros jurídicos. A auto-preservação do Estado confunde-se com a manutenção da estrutura econômica e política assegurada pelo direito positivo. Por isto, a argumentação no direito tem que considerar certos limites historicamente variáveis. Tais limites encontram-se nos princípios constitucionais estruturadores da ordem jurídica democrática. Mas mesmo tais princípios são suscetíveis de aperfeiçoamento e de arranjos em busca de equilíbrio entre os diversos valores que exprimem. É este o campo da ponderação de bens, que passa pelo teste da razoabilidade na decisão dos casos concretos. ${ }^{?}$

4 AZEVEDO, Plauto Faraco de. Justiça distributiva e aplicação do direito. Porto Alegre: Fabris, 1983, p. 113-114.

5 HOLMES, Oliver Wendell. The common law. Boston: Little, Brown, 1963, p. 5.

6 FAORO, Raymundo. A injustiça nos tribunais. Aula inaugural na Faculdade de Direito da UFRGS, em 20 de março de 1986. Porto Alegre: UFRGS, 1986, p. 8-9.

7 CANOTILHO, José Joaquim Gomes. Direito constitucional e teoria da Constituição. 3. ed. Coimbra: Almedina, 1998, p. 1161-1165. 
É este um ângulo fecundo, desenvolvido pelo constitucionalismo atual, mas a ele não se limita. A ponderação dos interesses já era tratada de modo acurado por François Gény, do ponto de vista do direito privado, criticando o automatismo da aplicação do direito preconizada pela Escola da Exegese. ${ }^{8}$ Tratava-se, como hoje se trata, de transcender a concepção positivista da Ciência do Direito, ligando o sistema legal a seus fundamentos, aferindo os valores que exprime e cuidando dos seus resultados, no julgamento dos casos concretos, em conformidade com as necessidades sociais.

Nada melhor do que o estudo da Hermenêutica Jurídica para ver-se o quanto o direito positivo tem-se modificado, a partir das valorações propostas pelos advogados e aceitas pelo prudente critério dos juízes, a tal ponto que se pode afirmar que muitas das salutares modificações, ocorridas no direito de família pátrio, resultaram de longo trabalho jurisprudencial, para tãosó aludir a este ramo do direito. É oportuno lembrar - e nunca é demais repeti-lo - que a Hermenêutica Jurídica só pode construir-se adequadamente entre dois extremos, que devem ser sempre evitados: nem o juiz pode-se converter em legislador, nem este pode ser tido como onipotente ou onisciente. É de se reservar um lugar especial à Hermenêutica Constitucional.

É nestes limites que o saber jurídico pode reviver, e eventualmente reconstituir o direito positivo, ${ }^{9}$ salvaguardando a segurança jurídica sem absolutizá-la, em direção ao aperfeiçoamento da ordem jurídica. Se a segurança jurídica não pode ser absolutizada, muito menos pode ser menosprezada, como bem sabem e sentem os práticos do direito e todos aqueles que, sendo partes no processo, buscam o reconhecimento de seus direitos, tal como prefigurados na ordem jurídica.

Mas é preciso também reconhecer, como ponderava Bergson, em texto

8 GENY, François. Méthodes et sources en droit privé positif. Préf. de Raymond Saleilles. 2. éd. rev. e mise au courant Paris: Librairie Générale de Droit et de Jurisprudence, 1950. t. 1, p. 1-12, passim. A primeira edição desta obra data de 1899 e a segunda, revista atualizada, data de 1919, tendo sido reimpressa em 1954. GENY, François. Science et technique en droit privé positif. Paris: Recueil Sirey, 1913. v. 1, p. 25-28.

9 Como assevera Larenz, "a ciência do direito desenvolve por si métodos de um pensamento 'orientado a valores', que permitem complementar valorações previamente dadas, vertê-las no caso singular e orientar a valoração que de cada vez é exigida, pelo menos em determinados limites, a tais valorações previamente achadas. Nesta medida são as valorações suscetíveis de confirmação e passíveis de uma crítica racional", sem que seus resultados possam "alcançar o mesmo grau de segurança e precisão de uma dedução matemática ou de uma medição empreendida de modo rigorosamente exacto". LARENZ, Karl. Metodologia da ciência do direito. Lisboa: Calouste, 1997, p. 3. 
reproduzido em "desenho livre", por Raymundo Faoro, que "a lei não pode, senão refugiando-se num tempo morto, afastar-se da sociedade, das exigências que lhe asseguram o movimento expressas em valores que não estão além da lei, mas dentro dela". A adaptação da lei aos casos concretos tem que ter por eixo a justiça, que "evocou sempre idéias de igualdade, de proporção, de compensação". Sem a justiça "a sociedade talvez pudesse subsistir, mas subsistiria pela violência, pela repressão, pelo medo, imobilizando a paz, sobre a qual repousa. Fora da justiça, ainda que as sanções da lei se apliquem, o homem será o lobo do homem, pela quebra do convívio fundado no consentimento e na cidadania." 10

A sutileza do trabalho jurídico, envolvendo conhecimento e interpretação de fatos e de leis, adequando estas aos contornos daqueles, caminhando pelo leito da segurança jurídica, percebendo-a como imantada pela justiça-, exige esmerada formação. $\mathrm{O}$ advogado não pode ser "a engrenagem mestra do aparelhamento do Estado", nem "um técnico destro a todos os malabarismos, a serviço de quaisquer interesses, espécie de tecnocrata do sofisma". $\mathrm{O}$ advogado há de recobrar o traço, que já o caracterizou, na história do Brasil, havendo de ser, "substancialmente, um intelectual", sendo a característica do intelectual "o anticonformismo, ainda que não revolucionário, ainda que nem sempre oposicionista". ${ }^{11}$

Limpado o horizonte intelectual dos antolhos positivistas, não há porque negar que a Ciência Jurídica tenha um comprometimento com a busca da justiça social. Feita esta ultrapassagem, o trabalho do jurista não se exaure nas abstrações, mas tem relevante papel social.

O extravio do discurso jurídico se dá pela aceitação do pensamento parcelar, que, além de cindir o direito positivo, o separa dos demais ramos do conhecimento. Ao revés, é essencial a admissão de investigações interdisciplinares, de modo a habilitar o jurista a compreender a totalidade do social. Sem esta compreensão, o jurista entenderá sempre insuficientemente o direito positivo. O conhecimento dos fatos, de seu encadeamento e de suas motivações, é imprescindível. Não se compreende o direito sem perquirir os fatos, pois é em função destes que se põe e se aplica o direito positivo.

\section{DISCIPLINAS PROPEDÊUTICAS}

Feitas estas considerações, chegase às disciplinas propedêuticas que concorrem à ampla formação do jurista, permitindo-lhe exercitar o raciocínio

10 FAORO, Raymundo. A injustiça nos tribunais. Aula inaugural na Faculdade de Direito da UFRGS, a 20 de março de 1986. Porto Alegre: UFRGS, 1986. p. 14.

11 FAORO, A injustiça..., p. 7. 
sobre suas estruturas conectadas ao quadro histórico a que se destinam e de que sofrem a influência. Assim se articula a compreensão do direito em uma perspectiva transpositivista, apta a interpretá-lo e aplicá-lo com sensibilidade humana.

Neste sentido, a disciplina de Introdução à Ciência do Direito assume relevância sem par, pelo seu caráter formativo, à condição que seus conteúdos sejam propícios ao entendimento da ordem jurídica, de sua estrutura, hierarquia, de seus princípios ou valores fundamentais. Para isto a Introdução é, em um primeiro momento, Teoria Geral do Direito, tratando das fontes, reservando lugar especial à jurisprudência. Em um segundo momento, é uma iniciação à Filosofia do Direito, propiciando uma idéia sucinta das diferentes correntes do pensamento jurídico. Em um terceiro momento, pode ser uma introdução ao Direito Comparado, mediante a exposição dos pressupostos básicos dos sistemas romano-germânicos (civil law) e da common law, deixando claro que a experiência jurídica não se restringe à tradição ocidental, precisando ser sensível à interculturalidade. É certo que nada disto pode ser feito sem que se atribua a esta disciplina o tempo necessário à maturação discente, em dois semestres.

Disciplina introdutória sempre foi o Direito Romano, beneficiando-se o profissional do direito com o conhecimento de seus institutos jurídicos fundamentais, historicamente considerados, de modo a perceber-se a ultrapassagem do ius civile ao ius gentium, e a seiva "jurisprudencial" do direito pretoriano, contraposta à codificação de Justiniano.

Noções de Economia Política (não de economia neoliberal) são essenciais para que o profissional do direito possa discernir a vulgata economicista vigente, ditada pelos organismos internacionais de crédito e "regulação" do comércio e difundida pela Universidade de Chicago e congêneres. Apregoando esta o livre comércio, a abertura total dos mercados, em que pese a múltipla disparidade entre eles, forra-se de matemática e estatísticas descontextualizadas, para impor sua mensagem estratificadora da configuração atual da sociedade internacional, que consagra a miséria da maioria, em favor da opulência de poucos potentados. À Economia Política, ao revés, cabe o exame crítico da globalização financeira vigente, aferindo a internalidade dos custos, revelando o artifício da sua externalidade, vale dizer, computando os pesados custos ambientais e sociais da vigente teoria econômica.

\section{DISCIPLINAS OBRIGATÓRIAS}

O ensino do Direito Constitucional abre o leque das disciplinas obrigatórias como estruturador da ordem jurídica $\mathrm{e}$ definidor dos direitos fundamentais, devendo ser capaz de apontar criticamente $o$ ataque à dimensão social destes e o menosprezo à efetividade de sua dimensão ambiental. Quanto à 
primeira, a cada dia melhor se percebe a fratura na Consolidação das Leis do Trabalho, que vem fazendo desaparecer "o sujeito para emergir tão-só a mão de obra contratada. Cada um por si, no mercado, disputando segundo suas capacidades e habilidades e assumindo a culpa de não ser um vencedor". ${ }^{12}$ É também crucial o exame do avanço das medidas provisórias, cujo excesso atenta contra o princípio cardeal da tripartição dos poderes.

Não pode faltar, no elenco das disciplinas obrigatórias, o Direito Ambiental, que tem como valor fundamental a preservação da vida. Tudo o que se possa dizer a este respeito será pouco, dada a relevância do interesse que protege, demandando consideração acurada tanto do ponto de vista do direito material quanto processual. Sua importância ímpar é perceptível na Constituição de 1988, que lhe consagra um capítulo de singular penetração.

É fundamental a História do Direito. Sem o fio condutor da história nada se compreende. É estudando-a que o profissional do direito pode adquirir uma visão do direito medieval - dos glosadores e pós glosadores -, do direito moderno - da era das codificações, das grandes constituições liberais, do Estado social, e da tendência neoliberal, regressiva, atual, agressora dos direitos fundamentais sociais, em nome da "sacralidade do mercado".
A Hermenêutica Jurídica constróise orientada aos diferentes métodos de solução das controvérsias e com os olhos voltados para a atividade jurisdicional - ao prudente arbitrio dos iuizes e seus limites, evitando o vezo do "leguleio amante da letra redonda da lei" (Cunha Gonçalves) ou subscrevendo a prática do "juiz-legislador".

À Filosofia do Direito cabe aprofundar as noções ministradas pela Introdução e pela História do Direito, tendo como objetivo favorecer a crítica racional do direito positivo, achegandose à vida e acautelando-se da tendência às elocubrações abstratas e ao fascínio dos modismos acadêmicos. Ponto de suma importância é a determinação das relações entre direito, moral e ética.

A importância do Direito Administrativo não necessita ser encarecida, tendo em vista os problemas e conceitos fundamentais com que lida, dentre os quais sobrelevam os de bem público, de ato administrativo, poder de polícia, atos e contratos administrativos, bens públicos, o de discricionariedade administrativa e controle judicial, etc. É nele que se reflete a questão da dimensão do Estado, posta pelo neoliberalismo como a necessidade do "Estado mínimo" como a panacéia para a solução de todos os males. Neste sentido é relevante o exame crítico das denominadas Agências Reguladoras.

O Direito Tributário tem singular lugar no ordenamento jurídico,

12 COUTINHO, Aldacy Rachid. Globalização e direito do trabalho. Direito e Democracia, Canoas: v. 1, n. 1, p. 163-176, 2000. 
discriminando os tributos a serem cobrados e os devolvendo sob a forma de serviços à comunidade. Para ser bem compreendido tem que ser trabalhado com a Teoria da Constituição. Da adequada estruturação positiva do Direito Tributário dependem o bom andamento da coisa pública e a salvaguarda da integridade da federação.

No que toca ao Direito Penal, é de tentar-se, sempre, a conexão de seu estudo dogmático com a Criminologia e a Sociologia, para que não se percam de vista as múltiplas motivações do crime, de modo a permitir o questionamento das diferentes políticas criminais.

O Direito Internacional Público está a necessitar atenção especial, visto que tem sido literalmente pisoteado, apesar de sua função nitidamente civilizatória. O mundo globalizado não pode ser governado pela força bruta. $O$ fundamento do direito acha-se no respeito à dignidade humana, como se percebe e se anota nas constituições democráticas e nos tratados internacionais.

No Direito Material, é de se enfatizar o estudo dos novos contornos do Direito de Família, decorrentes do avanço da biologia e das novas configurações de vários de seus institutos, a merecerem crítica e prudente aferição.

No Direito Processual, cuja importância é inconteste, é desejável que seu ensino sublinhe seu caráter instrumental, para que de seu aprendizado não resulte a substituição do formalismo pela substância dos interesses em litígio. A forma tem como único sentido favorecer a segurança jurídica. $O$ processo não pode ser utilizado como artifício para encobrir dificuldades e fugir da responsabilidade das decisões. O processo é meio de composição de litígios e não fim em si. ${ }^{13}$

\section{DA PRÁTICA JURÍDICA}

Todas as considerações expendidas, enfatizando a imprescindibilidade de disciplinas, tanto propedêuticas quanto estruturais, não teriam sentido se não servissem ao caráter prático do direito positivo e a seu aspecto profissionalizante.

Todo discurso jurídico que não tenha em vista as diversas profissões jurídicas - Judicatura, órgãos do Ministério Público, advocacia pública ou privada, magistério jurídico, Defensoria Pública, consultoria jurídica pública ou privada, etc. - não serve às finalidades práticas do direito.

É tendo em vista a necessidade do prudente e eficaz desempenho dessas funções que se trata de instrumentalizar o profissional do direito com as noções essenciais ao seu bom desempenho.

Com esta finalidade, estrutura-se, de modo paulatino, à medida em que se desenvolve o curso, a Prática Jurídica, a qual, de nenhum modo, se exaure na memorização dos manuais de elaboração de petições, necessitando oferecer ao futuro profissional meios de estruturação do raciocínio, habilitando-o à arte da argumentação, que é o método peculiar ao direito, como adverte Perelman. $\mathrm{O}$ 
desenvolvimento da argumentação visa à solução das questões jurídicas, tanto na área consultiva quanto na área judicante. Faz-se ela para solver litígios, para aventar soluções práticas a problemas práticos, envolvendo fatos, valores e normas (Reale). Não pode, por isto, esgotar-se em distinções e subdistinções sibilinas, que só servem para aprofundar a descrença do direito pelo povo. Diante dos processos, o profissional do direito precisa ser servido por uma dogmática transpositivista, capaz de distinguir os interesses em questão, apreendendolhes o valor, para poder entre eles optar.

Nestas condições, teoria e prática do direito são correlativas. Como escreve Roberto Lyra Filho, não "há prática decente sem uma teoria válida em que se arrime. Lembrava, há muito, Ortega que toda teoria é teoria da prática e a prática não é mais do que práxis da teoria". ${ }^{14}$

\section{REFERÊNCIA A ALGUMAS DISCIPLINAS OPTATIVAS}

Muitas das disciplinas consideradas optativas, na verdade o são por injunção temporal, sem que se possa negar sua importância à teoria ou à prática do direito. Dentre elas podem-se enumerar: Direito Internacional Privado, Direito Agrário, Previdenciário, da Infância e da Juventude, Bancário, História das Idéias Políticas, Sociologia Jurídica, Organizações Internacionais, etc. A montagem curricular a este respeito, constitui trabalho delicado a demandar cuidadoso critério, segundo a ênfase peculiar a cada curso.

\section{DURAÇÃO DO CURSO}

Por mais extemporâneo que possa parecer, no contexto de pragmatismo vigente, a Universidade Pública precisa ter em vista, se necessário for, o alongamento da duração do curso, de vez que seu compromisso não é outro senão o da formação de egressos não só aptos ao exercício profissional, mas também capazes de discernir o sentido e o valor de seu trabalho e de mensurálo na tarefa de manutenção $\mathrm{e}$ aperfeiçoamento da democracia.

\section{CONSIDERAÇÕES FINAIS}

Estas reflexões supõem, como é evidente, a adequação de alguns conteúdos curriculares. Também não deixam de ter em consideração a necessidade de docentes aptos a realizá-las. É de se esperar que os cursos de Mestrado e Doutorado concorram, positivamente, neste sentido. Também se tem em mira que a docência não se pode dar de modo construtivo sem um trabalho de pesquisa e publicações correlato.

O preparo do professor, por maior que seja, não exclui o aspecto vocacional e uma perspectiva pedagógica aberta, em que a transmissão do conhecimento seja simultaneamente aprendizado.

14 LYRA FILHO, Roberto. Problemas atuais do ensino jurídico. Brasília: Obreira, 1981, p. 16. 
